\title{
PREVALENCE OF ATRIAL FIBRILLATION, ORAL ANTICOAGULATION PRESCRIPTION AND ASSOCIATED FACTORS IN BRAZILIAN OLDER ADULTS
}

\author{
Prevalência de fibrilação atrial, indicação de \\ anticoagulação oral e fatores associados em idosos brasileiros
}

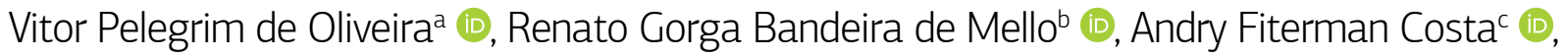 \\ Roberta Rigo Dalla Corte ${ }^{\mathrm{b}}\left(\mathbb{D}\right.$, Francine da Rocha Flores ${ }^{\mathrm{b}}$ (1), Nicóli Bertuol Xavier ${ }^{\mathrm{b}}(\mathbb{C}$, \\ Nathália Marzotto Nunes ${ }^{\mathrm{b}}$ (D), Emilio Hideyuki Moriguchib (i)
}

INTRODUCTION: Atrial fibrillation increases five times the risk of stroke. Anticoagulation reduces the incidence of cerebrovascular events. However, many patients do not receive thromboprophylaxis. OBJECTIVES: To estimate the prevalence of atrial fibrillation in the older patients at a Brazilian university hospital and the proportion of anticoagulation prescription. Secondary objectives were to identify the therapeutic options, the main reasons for non-prescription and the factors associated with ineffectiveness or lack of treatment. METHODS: This was a cross-sectional study with a consecutive sample of 1,630 outpatients selected at Hospital de Clínicas de Porto Alegre between April and June of 2017. Atrial fibrillation was identified in 220 (13.50\%) individuals. Medical records from 145 patients were accessed, followed by a telephone interview. The association between variables and outcomes was checked using the Mann-Whitney's U Test and a chi-squared test. RESULTS: The prevalence of atrial fibrillation was $13.50 \%$. Anticoagulation therapy was prescribed in $77.93 \%$ of cases. In $76.11 \%$ of patients, warfarin was the chosen drug. There was a tendency towards no prescription in patients with previous bleeding $(R R=2.32 ; 95 \% \mathrm{Cl} 0.95-5.64 ; \mathrm{p}=0.06)$ and falls $(\mathrm{RR}=2.02 ; 95 \% \mathrm{Cl} 0.82-5.03 ; \mathrm{p}=0.08)$. We found an association between reduced functional capacity (Barthel's Activities of Daily Living Score < 80) and higher rate of anticoagulation in therapeutic target $(\mathrm{RR}=0.22 ; 95 \% \mathrm{Cl} 0.06-0.87 ; \mathrm{p}=0.04)$. CONCLUSION: The prevalence of atrial fibrillation in this population was $13.50 \%$ and in $77.93 \%$ of cases anticoagulant were prescribed. Functional impairment was associated with a higher rate of anticoagulation in therapeutic target.

KEYWORDS: atrial fibrillation; anticoagulants; prevalence; geriatrics; cerebral infarction.

INTRODUÇÃO: A fibrilação atrial aumenta o risco de eventos cerebrovasculares em cinco vezes. A anticoagulação reduz a incidência e a gravidade desses eventos, entretanto muitos pacientes deixam de receber tromboprofilaxia. OBJETIVOS: Avaliar a prevalência de fibrilação atrial em pacientes idosos acompanhados em um hospital universitário e identificar o percentual desses pacientes com prescrição de anticoagulantes. Os objetivos secundários foram identificar as opções terapêuticas, as justificativas para não indicar o uso e os fatores associados à ineficácia e/ou ausência de tratamento. METODOLOGIA: Em estudo transversal, uma amostra consecutiva de 1.630 pacientes do Hospital de Clínicas de Porto Alegre foi rastreada entre abril e junho de 2017. Fibrilação atrial foi identificada em $220(13,50 \%)$ indivíduos, dos quais 145 foram avaliados com base na revisão de prontuários e questionário telefônico. A associação entre as variáveis e os desfechos foi analisada por meio do Teste U de Mann-Whitney e do teste do qui-quadrado. RESULTADOS: A prevalência de fibrilação atrial foi de 13,50\%. Em 77,93\%, havia anticoagulante prescrito. Em 76,11\% dos anticoagulados, a opção foi varfarina. Houve tendência de não prescrição para idosos com histórico de sangramento (risco relativo - $R R=2,32$; índice de confiança de 95\% - IC95\% 0,95 - 5,64; $p=0,06$ ) e quedas (RR = 2,02; IC95\% 0,82 - 5,03; $p=0,08$ ). Houve associação significativa entre maior grau de limitação funcional e maior índice de tratamento no alvo terapêutico (razão de prevalência - RP = 0,22; IC95\% 0,06 - 0,87; p = 0,04). CONCLUSÃO: A prevalência de fibrilação atrial foi de 13,5\% e, em 77,93\% dos casos, havia prescrição de anticoagulante. Houve associação entre incapacidade funcional e melhor índice de anticoagulação no alvo terapêutico. PALAVRAS-CHAVE: fibrilação atrial; anticoagulantes; prevalência; geriatria; infarto cerebral.

a Hospital de Clínicas de Porto Alegre - Porto Alegre (RS), Brazil.

buniversidade Federal do Rio Grande do Sul - Porto Alegre (RS), Brazil.

cHospital de Clínicas de Porto Alegre - Porto Alegre (RS), Brazil.

Correspondence data

Vitor Pelegrim de Oliveira - Hospital de Clinicas de Porto Alegre - Rua Ramiro Barcelos, 2.350 - Bom Fim - CEP: 90035-903 - Porto Alegre (RS), Brasil. E-mail: vitorpelegrim@gmail.com

Received on: 05/22/2020. Accepted on: 07/21/2020

https://doi.org/10.5327/Z2447-212320202000065 


\section{INTRODUCTION}

Atrial fibrillation $(\mathrm{AF})$ is the most common type of cardiac arrhythmia, and its prevalence increases progressively with aging. It is uncommon before the age of 60 , but present in up to $10 \%$ of patients aged 80 years and older. ${ }^{1} \mathrm{AF}$ increases five times the risk of stroke and is associated with high rates of morbidity and mortality. ${ }^{1,2}$

Oral anticoagulation by administration of vitamin $\mathrm{K}$ antagonist (warfarin or phenprocoumon) or one of the direct oral anticoagulants (DOAC) (dabigatran, rivaroxaban, apixaban or edoxaban) significantly reduces the risk of cerebral vascular events, with low incidence of clinically significant bleeding. ${ }^{3-10}$

Despite the proven benefits of oral anticoagulation, many patients do not receive treatment even without a clear contraindication. Among older adults, precisely the group at highest risk of thromboembolic events, non-prescription of thromboprophylaxis is even more frequent and tends to be the consequence of an erroneous perception of treatment's risk versus benefit.

This is a worldwide phenomenon with strokes, deaths and neurological sequelae as consequences that could be prevented. ${ }^{11,12}$ More than 33 million people have AF worldwide, and this prevalence is expected to double by $2050 .{ }^{11}$ When compared to others causes of stroke, events related to $\mathrm{AF}$ are more recurrent, responsible for more extensive and severe cerebral damage, and result in greater morbidity (such as permanent neurological sequelae and disability) and mortality. ${ }^{13,14}$

Data regarding prevalence of $\mathrm{AF}$ and anticoagulation prescription in Brazilian older adults is scarce (or lacking). A study carried out in the state of Minas Gerais evaluated the electrocardiographic records performed by a telemedicine service in 262,000 primary care patients. ${ }^{15}$ The prevalence of $\mathrm{AF}$ was $1.8 \%$ in the total population, reaching almost $15 \%$ of nonagenarian men. In that study, only $1.5 \%$ of patients with AF reported the use of anticoagulants and 3\% used acetylsalicylic acid (ASA). Among the possible justifications raised by the authors for the low prevalence of oral anticoagulation, one can mention the scarce access to health resources in isolated communities, the difficulty of primary care physicians to control the levels of anticoagulation, and possible lack of diagnosis, which could be revealed by the electrocardiogram included in the analysis.

Even in tertiary centers, the prescription of thromboprophylaxis is poorly documented. In studies carried out in university centers specialized in cardiology, the indication for treatment occurred in just over half of the cases. ${ }^{16,17}$
The main objective of this study was to identify the prevalence of AF in 60 years or older patients, in a tertiary-level internal medicine and geriatrics outpatient clinics at Hospital de Clínicas de Porto Alegre (HCPA), and the percentage of these patients with oral anticoagulation prescription. The secondary objectives were to identify the treatment options chosen for anticoagulation, the reasons pointed as contraindication to the use, and the factors possibly associated with less efficacy or lack of treatment.

\section{METHODS}

Cross-sectional study carried out in two stages, as described below:

- Consecutive review of medical records of all patients aged 60 years and older and with appointments scheduled at the HCPA internal medicine and geriatrics outpatient clinics between April 1 and June 30,2017, aiming to identify the prevalence of AF. The diagnosis was defined as follows: arrhythmia stated in the medical record, with a condition identified on the last available electrocardiogram (ECG) or on a 24-hour Holter monitoring;

- Among patients with AF, additional data were included for the prescription assessment phase of anticoagulants and associated factors: nonvalvular AF and CHA2DS2Vasc $\geq 2$ in women or $\geq 1$ in men. Exclusion criteria were the presence of another indication for oral anticoagulation (current or recurrent venous thromboembolism, intracavitary thrombus, portal venous thrombosis, mechanical valve prostheses or thrombophilia). Patients who met the eligibility criteria were invited to participate in the study on the day of their medical appointment. After the consent of participants or care givers, their medical records were analyzed for demographic data, record anticoagulation prescription, medication prescribed, justification for non-prescription among those not on current treatment, data for calculating the $\mathrm{CHA}_{2} \mathrm{DS}_{2}$-VASc score, score HASBLED, fraction of prothrombin time (PT) exams on target, comorbidities (Charlson index) and number of drugs in use.

Between 15 and 60 days after the first contact to sign the informed consent form, due to logistical issues, a standardized questionnaire was applied by phone to obtain information about falls (history of falls in the previous year and gait difficulties/balance), bleeding, hospitalization, need for blood transfusions and functional independence through Barthel's 
scales of basic activities of daily living (BADL) and instrumental activities of daily living (IADL). The information was provided by the patients or by a family member who was aware of their health history. A team of four trained researchers (a physician, a nutritionist and two undergraduate medical students) applied the questionnaires. A senior researcher audited the interviews and reviewed the completed forms. All patients signed an informed consent form accepting to participate in the study.

\section{Statistical analysis}

The data were analyzed using version 21.0 of the Statistical Package for the Social Sciences (SPSS) for Windows. As this is a cross-sectional study to identify the prevalence of AF, the percentage of patients undergoing thromboprophylaxis and the main reasons for not instituting therapy, first plans were to assess the universe of patients treated at the HCPA internal medicine and geriatrics services. Therefore, as all possible individuals were screened for inclusion in the present study, the sample size was not calculated. A descriptive analysis was performed providing absolute and relative frequencies for categorical data and the mean \pm standard deviation for continuous variables. The distribution of variables was assessed by the Shapiro-Wilk test $(\mathrm{p}<0.05)$ and, because they are asymmetric, the analysis of association between continuous variables and prescription of anticoagulation was made with the Mann-Whitney U test. Associations between categorical variables and the outcome "no prescription of anticoagulant" were analyzed by a chi-squared test. The level of significance was $5 \%$.

\section{Ethical approval}

The project of this study was approved by the HCPA Research Ethics Committee under protocol 63926116.1.0000.5327. All participants were presented with the informed consent form, and their inclusion in the research was dependent on the agreement and signature of the document by patients or care givers.

\section{RESULTS}

A total of 1,630 consultations were assessed using medical records, ECG and/or 24-hour Holter monitoring for the diagnosis of AF. Two hundred and twenty patients had AF. Thirty-five patients missed the first evaluation visit, 27 refused to participate in the study and 13 were excluded because they had other indications for anticoagulation. In total, 145 patients signed the informed consent form and were included in the sample (Figure 1).
The mean age of the population evaluated was 76.34 years $( \pm 8.16)$ and $51.03 \%$ of the sample were men. Mean $\mathrm{CHA}_{2} \mathrm{DS}_{2}-$ VASc was $4.61( \pm 1.56)$ and mean HAS-BLED score was 2.87 $( \pm 0.80)$. The average number of medications in use was 8.30 $( \pm 2.67)$ per patient and mean Charlson comorbidity index was 2.69 ( \pm 1.97 ).

The prevalence of oral anticoagulation prescription was $77.93 \%$, practically identical between both outpatient clinics (77.89\% in internal medicine and $78 \%$ in geriatrics). There was no statistically significant difference between patients on anticoagulation and those who were not in treatment when it comes the variables sex, $\mathrm{CHA}_{2} \mathrm{DS}_{2}-\mathrm{VASc}$, HAS-BLED, medical specialty, number of medications in use, and comorbidities. Among patients not on anticoagulation, $65.5 \%$ were on antiplatelet therapy versus $16.81 \%$ on anticoagulants (Table 1). Among anticoagulants with vitamin $\mathrm{K}$ antagonists (warfarin or phenprocoumon), 88.76\% were being followed up at the HCPA anticoagulation control clinic (AMA). The drug most frequently chosen for anticoagulation was warfarin (76.11\%), followed by rivaroxaban (15.93\%), apixaban (4.42\%), phenprocoumon (2.65\%) and dabigatran (0.88\%) (Figure 2).

Among the reasons for not prescribing thromboprophylaxis, the most prevalent was "risk of bleeding", which, added to "previous bleeding", represented $21.88 \%$ of all justifications. Almost a third (31.25\%) of the patients' records without

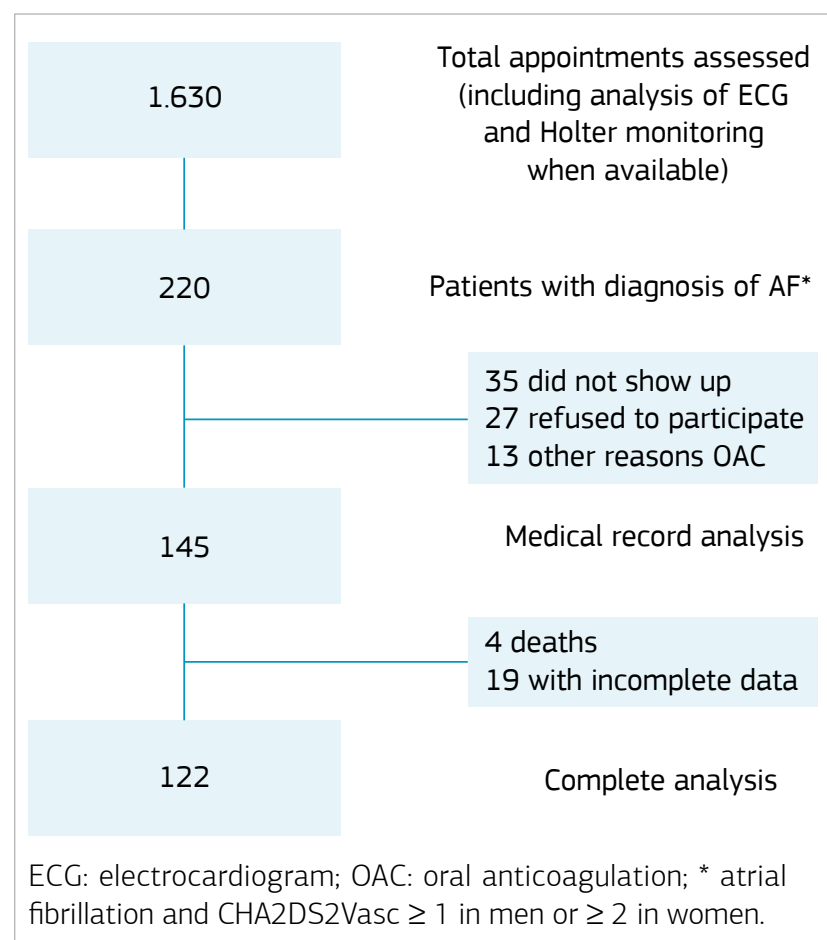

Figure 1. Patient flow diagram illustrating the total appointments and complete analysis enrolled in this study. 
anticoagulation did not have the reason for the non-indication recorded. In $12.50 \%$ of patients, the justification was "social difficulty" (Figure 3).

In total, 122 patients answered the telephone questionnaire. There were four deaths between recruiting and contacting researchers. Nineteen patients were not found or could not respond when contacted by the research team because they were absent or unable to (minimum of 10 attempts by at least two different researchers). There was no refusal to answer the questionnaire. We found no association between the factors under study and non-prescription of anticoagulants. However, there was a tendency not to prescribe anticoagulants to patients with history of falls (prevalence ratio $-\mathrm{PR}=2.02 ; 95 \% \mathrm{CI} 0.82-5.03, \mathrm{p}=0.08$ ) and patients with history of bleeding $(\mathrm{PR}=2.32 ; 95 \% \mathrm{CI}$ $0.95-5.64, \mathrm{p}=0.06)($ Table 2).

Regarding the efficacy of anticoagulation with vitamin $\mathrm{K}$ antagonists, there was an association between a better

Table 1. Characteristics of older adults (aged 60 years and older) with atrial fibrillation from a Brazilian tertiary outpatient unit.

\begin{tabular}{|c|c|c|c|}
\hline Variable & $\begin{array}{l}\text { With anticoagulant } \\
\text { prescription }\end{array}$ & $\begin{array}{c}\text { Without anticoagulant } \\
\text { prescription }\end{array}$ & $\begin{array}{l}\text { Total } \mathrm{n}(\%) \text { or mean } \\
\text { (standard deviation) }\end{array}$ \\
\hline All & $113(77.93 \%)$ & $32(22.07 \%)$ & $145(100 \%)$ \\
\hline Males & $54(47.79 \%)$ & $21(65.63 \%)$ & $74(51.03 \%)$ \\
\hline Age & $76.39( \pm 0.22)$ & $7 . .16( \pm 8.47)$ & $76.34( \pm 8.16)$ \\
\hline CHA2DS2-VASC & $4.59( \pm 1.47)$ & $4.44( \pm 2.00)$ & $4.61( \pm 1.56)$ \\
\hline HAS-BLED & $2.81( \pm 0.79)$ & $3.03( \pm 0.93)$ & $2.87( \pm 0.80)$ \\
\hline Internal Medicine & $74(77.89 \%)$ & $21(22.11 \%)$ & $95(65.52 \%)$ \\
\hline Geriatrics & $39(78.00 \%)$ & $11(22.00 \%)$ & $50(34.5 \%)$ \\
\hline Use of antiaggregant (ASA or clopidogrel) & 19 (16.81\%) & $20(62.50 \%)$ & 39 (26.90\%) \\
\hline Double anti-aggregation (ASA + clopidogrel) & $0(0.00 \%)$ & $1(3.13 \%)$ & $1(0.69 \%)$ \\
\hline Number of medications & $8.34( \pm 2.55)$ & $7.78( \pm 3.01)$ & $8.30( \pm 2.67)$ \\
\hline Comorbidities (Charlson) & $2.41( \pm 1.80)$ & $3.03( \pm 2.24)$ & $2.69( \pm 1.97)$ \\
\hline
\end{tabular}

ASA: acetylsalicylic acid.

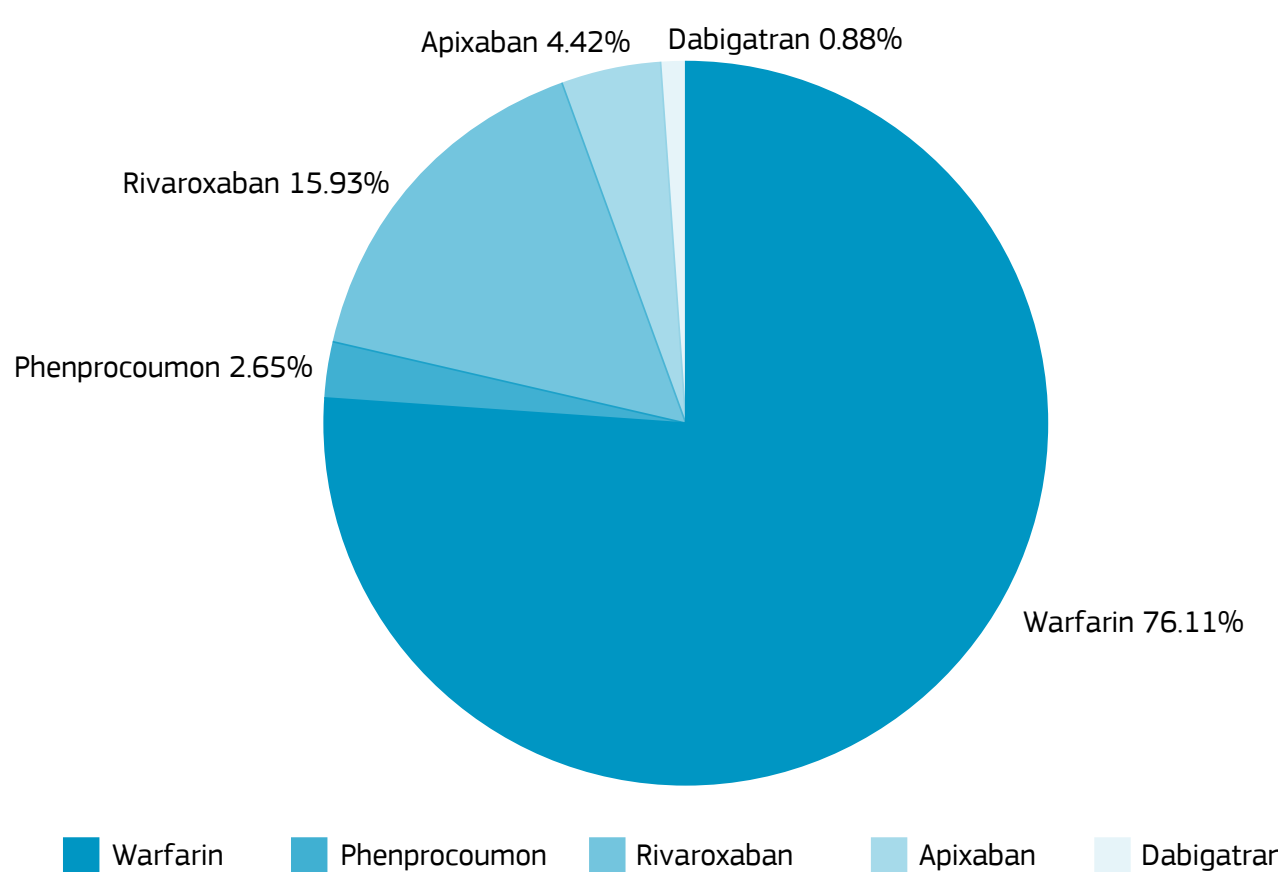

Figure 2. Anticoagulation options. 
index of prothrombin time fraction on target in patients with functional impairment. In our sample, $50 \%$ of the patients with functionality calculated by Barthel below 80 had a prothrombin time fraction on target above $60 \%$, while among patients with scores above 80 , only $18.2 \%$ had prothrombin time fraction on target above $60 \%(\mathrm{PR}=0.22 ; 95 \% \mathrm{CI} 0.06$ $0.87 ; \mathrm{p}=0.04)($ Table 3$)$.

\section{DISCUSSION}

Data from 1,630 patients from the geriatrics and internal medicine outpatient clinics scheduled for the study period were evaluated, and 220 (13.50\%) of them had AF. The prevalence of anticoagulation prescription among patients with AF was $77.93 \%$. The main reasons for not prescribing oral anticoagulation (OAC) were previous bleeding (15.63\%) and social issues (12.50\%). In $31.25 \%$ of patients without anticoagulation, there was no recorded justification for such decision. It was not possible to identify predictive factors for non-therapeutic indication in this sample. The most prescribed medication was warfarin (76.11\%), followed by rivaroxaban (15.93\%) and apixaban (4.42\%). Combined DOACs accounted for $21.23 \%$ of pharmacological options and its use is increasing in our therapeutic arsenal, even considering the high costs in a scenario with a significant number of low-income patients.
Table 2. Prevalence ratio for non-prescription of oral anticoagulant options in a Brazilian sample of older patients with atrial fibrillation from a tertiary outpatient unit $(n=145)$.

\begin{tabular}{l|c|c|c} 
& $\begin{array}{c}\text { Prevalence } \\
\text { ratio }\end{array}$ & $95 \% \mathrm{Cl}$ & p value \\
\hline Male & 1.52 & $0.54-4.24$ & 0.43 \\
\hline Age > 75 years & 0.78 & $0.29-2.09$ & 0.62 \\
\hline HAS-BLED > 3 & 1.81 & $0.58-5.64$ & 0.31 \\
\hline Charlson > 3 & 1.40 & $0.53-3.71$ & 0.50 \\
\hline History of falls & 2.02 & $0.82-5.03$ & 0.08 \\
\hline $\begin{array}{l}\text { Difficulty of walking } \\
\text { or balance }\end{array}$ & 1.87 & $0.57-6.16$ & 0.31 \\
\hline History of bleeding & 2.32 & $0.95-5.64$ & 0.06 \\
\hline Barthel < 80 & 1.28 & $0.25-6.47$ & 0.77 \\
\hline Lawton < 18 & 1.10 & $0.24-5.11$ & 0.90 \\
\hline
\end{tabular}

95\%Cl: 95\% confidence interval.

Table 3. Effectiveness of anticoagulation with vitamin $\mathrm{K}$ antagonists: fraction of prothrombin time examination on the therapeutic aim> $60 \%$ of the time.

\begin{tabular}{l|c|c|c} 
Condition & $\begin{array}{c}\text { Prevalence } \\
\text { ratio }\end{array}$ & $95 \% \mathrm{Cl}$ & p value \\
\hline Female & 2.60 & $0.91-7.45$ & 0.06 \\
\hline Age $<75$ & 0.46 & $0.16-1.36$ & 0.12 \\
\hline Charlson $<3$ & 1.43 & $0.50-4.09$ & 0.34 \\
\hline Followed up at AMA & 1.54 & $0.43-5.63$ & 0.36 \\
\hline Barthel $>80$ & 0.22 & $0.06-0.87$ & 0.04 \\
\hline Lawton $>18$ & 0.34 & $0.11-1.05$ & 0.06 \\
\hline
\end{tabular}

AMA: HCPA Anticoagulation Clinic; 95\%Cl: 95\% confidence interval.

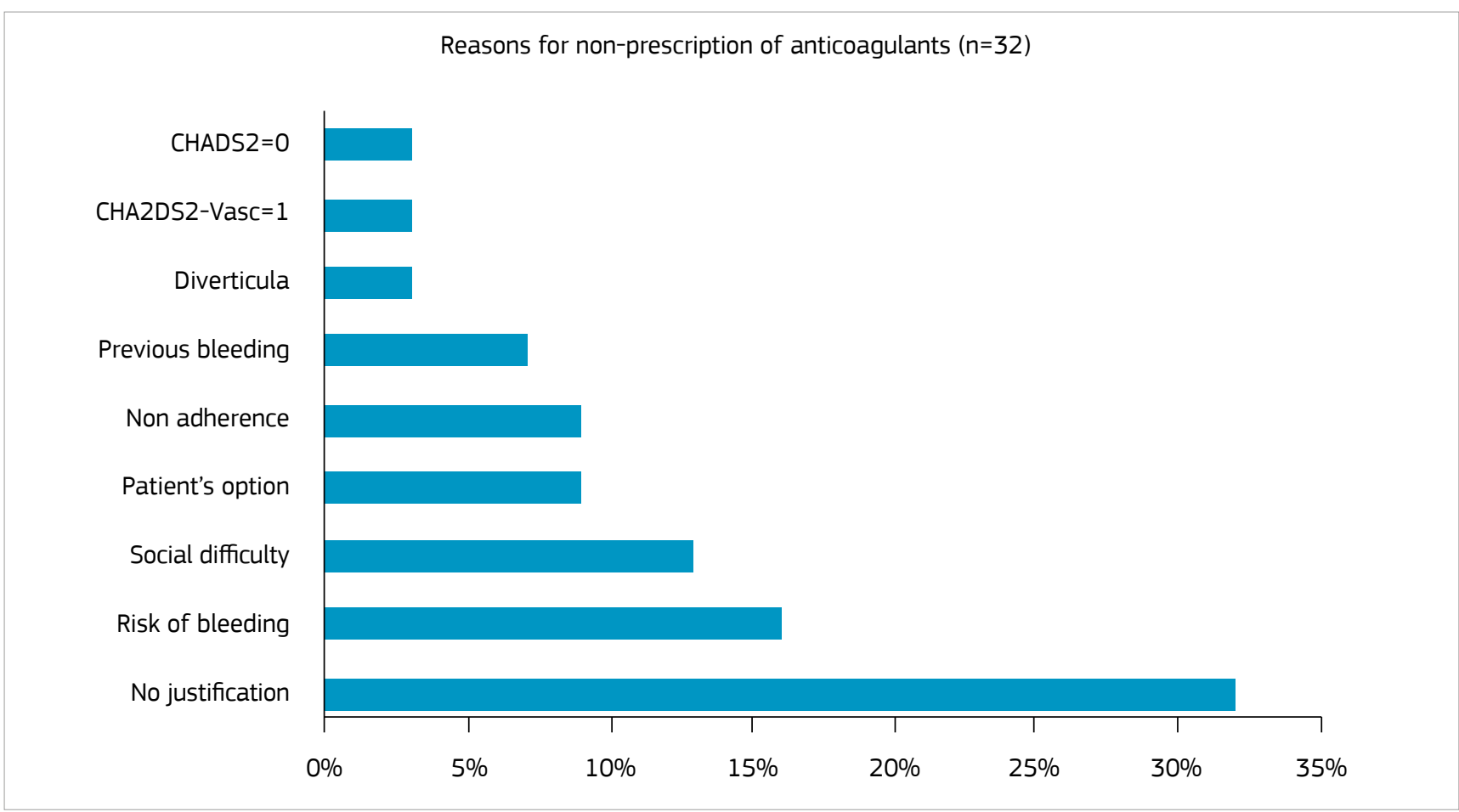

Figure 3. Justifications for non-prescription of oral anticoagulation $(n=32)$. 
The medical decision to prescribe anticoagulant medications for older adults should be made after carefully considering the potential risks and benefits of the treatment. Pharmacodynamic changes (lower glomerular filtration rate, reduced muscle mass, increased fat and reduced body water), polypharmacy and adherence difficulties make the prescription of these drugs more complex in older patients. Reduced mobility, in addition to difficulties of patients to access health services to monitor prothrombin time, increases the risk of falls. All these factors induce an amplified perception of risk, resulting in underprescription of treatment and increased exposure to serious events, such as physical dependence or death secondary to thromboembolic events. The real risk of serious adverse events is low, and anticoagulation should be considered even in patients at increased risk of bleeding. ${ }^{18,19}$

Although the highest risk of falls is associated with the highest risk of bleeding, the absolute risk is low in these patients and, in a previous study that evaluated this treatment option in patients at risk of falls, no significant difference was observed between the groups treated with warfarin, ASA and without treatment. ${ }^{20}$ Patients with CHADS2 $\geq 2$ benefited from anticoagulation even at high risk of falls. In another study, it was estimated that 295 falls in one year would be necessary for the risk of bleeding to outweigh the benefit of thromboprophylaxis. ${ }^{21}$

The STOPP/START ${ }^{22}$ initiative by the European Union Geriatric Medicine Society (EUGMS), which aims to minimize inappropriate prescriptions in older patients, recommends the use of warfarin in patients over 65 years of age with $\mathrm{AF}$, as long as there is no contraindication, placing ASA as a second option. However, it is not clear which contraindications could contribute to the mistaken perception that ASA would be a lower risk option and/or with similar effectiveness.

The study Birmingham Atrial Fibrillation Treatment of the Aged (BAFTA) from 2007 compared prophylaxis with ASA versus warfarin in 973 patients over the age of 75 . The group that received oral anticoagulation had the number of strokes reduced compared to the group that received ASA. There was no significant difference in bleeding events between groups. These findings reinforce that the option of monotherapy with ASA should rarely be considered. ${ }^{23}$

HCPA has an outpatient clinic dedicated exclusively to anticoagulation monitoring, which may partly explain the high percentage of patients with thromboprophylaxis (77.93\%), higher than described in previous studies. ${ }^{15-19,24}$ In a study carried out at Instituto do Coração of the University of São Paulo (InCor/USP), ${ }^{16}$ a tertiary center specialized in cardiology, only $57.8 \%$ of fibrillated patients had a prescription for oral anticoagulation. Even when considered at higher risk, with history of stroke, the percentage of treated patients did not exceed $60.4 \%$. In another study carried out in the city of Canoas, among 155 patients with CHA2DS-VASc $\geq 2$ only $37.6 \%$ had anticoagulation prescription, and in those with $\mathrm{CHA}_{2} \mathrm{DS}_{2}-\mathrm{VASc} \geq 5$ the indication for thromboprophylaxis dropped to $15 \% \cdot{ }^{17}$ In that same study, patients being followed up with neurologists, family doctors or general practitioners had extremely low prescription rates $(0,18.7$ and $31.2 \%$, respectively), while the indication for anticoagulation reached $79.4 \%$ in those treated by cardiologists.

In the systematic review by Ogilvie et al. ${ }^{18}$, which analyzed 54 articles related to risk of stroke and prescription of anticoagulation, it was evidenced that the underprescription of thromboprophylaxis is a worldwide phenomenon. 21 out of 29 studies with high-risk patients (history of stroke) reported indication for anticoagulants below $60 \%$.

The study by InCor ${ }^{16}$ also signaled the lack of clear justifications for not indicating anticoagulant therapy. In this study, one third of the patients without treatment had no reasons pointed in their medical records supporting the contraindication to thromboprophylaxis. Another justification commonly used in our country is social difficulty, which considers factors such as the ability to adhere to treatment and prothrombin time monitoring. Social difficulty was pointed in $12.5 \%$ of untreated patients, however such justification depends on a subjective judgment of the prescriber.

Despite the absence of statistical significance, there was a greater tendency for non-prescription in patients with a history of bleeding and falls in the previous year. The number of patients without a prescription for oral anticoagulation under the initial expectation ended up limiting the power of the study to assess these factors.

The association between impaired functionality and greater anticoagulation efficacy assessed by the prothrombin time index on target could be explained by the administration of drugs by third parties, ensuring greater adherence. A perception of a more adequate care structure could also encourage the prescriber to recommend treatment even in patients with a higher degree of dependence. However, this finding should be interpreted with caution due to the reduced number of patients with low functionality being monitored in the selected outpatient clinics.

The potential limitations of the study stem from its sample size and are inherent to the design. The telephone evaluation can be pointed out as a potential interference, even though the scales used to evaluate functionality (Barthel and Lawton) are validated for this type of application. ${ }^{25,26}$ In any case, the number of participants was adequate to respond to the main objectives, which allowed detailed descriptive analyses of the factors under study. 
It should also be noted that the results reflect the reality of a tertiary care scenario at a university hospital in a large center, and studies that assess the prescription habit in primary care are essential to estimate the real dimension of the risk of cardioembolic events in a larger portion of the Brazilian population. In this way, it would be possible to plan public health policies that would facilitate access to thromboprophylaxis, such as the incorporation of DOAC, which does not require control by laboratory tests, to the list of medications in the Brazilian Unified Health System (SUS). The increase in coverage of thrombophylaxis would mean a consequent reduction in the number of cerebrovascular events, neurological sequelae and deaths, with a significant economic impact.

\section{CONCLUSION}

Patients with AF being followed up at the tertiary outpatient clinics of internal medicine and geriatrics at HCPA, treated by SUS, are linked to a higher prevalence of oral anticoagulation prescription than previously described in the literature. Warfarin is the most frequently prescribed medication (76.11\%), and direct anticoagulants are a treatment option in $21.23 \%$ of cases. One third of patients without treatment have no reason for this decision recorded in their medical files. Risk of bleeding risk and social difficulty are the most frequent criteria for not prescribing thromboprophylaxis. There were no statistically significant associations between the predictors sex, age, functionality, history of falls, changes in gait or balance, comorbidities, number of drugs in use, previous bleeding episodes, $\mathrm{CHA}_{2} \mathrm{DS}_{2}$-VASc or HASBLED and no indication of anticoagulation. There was a non-significant tendency of association between non-prescription of anticoagulation for patients with previous history of bleeding and falls. We found an association between worse functionality and better efficacy of anticoagulation, as assessed by the fraction of prothrombin time scans on the therapeutic range.

\section{CONFLICT OF INTERESTS}

Emilio Hideyuki Moriguchi has no conflict of interest related to the theme of this article. He participates in clinical studies subsidized by AstraZeneca, Merck Sharp \& Dohme, Novartis, Pfizer, and Daiichi Sankyo is a member of the advisory boards of Biolab, Kowa, Lilly, Merck Sharp \& Dohme and Daiichi Sankyo laboratories and gives educational lectures subsidized by AstraZeneca, Biolab, Kowa, Merck Sharp \&Dohme, Novartis, Pfizer and Daiichi Sankyo. *Personal grants resulting from this activity are donated to volunteering and charities.

The other authors declare no conflict of interest.

\section{FUNDING}

None.

\section{AUTHORS' CONTRIBUTION}

VPO: study conception and design, data collection, analysis and interpretation and final writing. RGBM: study conception and design, data analysis and interpretation and final writing. AFC: study conception and design, data analysis and interpretation. RRDC: study conception and design, data analysis and interpretation. FRF: data collection, analysis and interpretation. NBX: data collection, analysis and interpretation. NMN: data collection, analysis and interpretation. EHM: study conception, design and final writing.

\section{REFERENCES}

1. Go AS, Hylek EM, Phillips KA, Chang Y, Henault LE, Selby JV, et al. Prevalence of diagnosed atrial fibrillation in adults: national implications for rhythm management and stroke prevention: the AnTicoagulation and Risk Factors in Atrial Fibrillation (ATRIA) Study. JAMA. 2001;285(18):2370-5. https://doi.org/10.1001/ jama.285.18.2370

2. Pritchett ELC. Management of Atrial Fibrillation. Review Article. N Engl J Med. 1992;326:1264-71. https://doi.org/10.1056/ NEJM199205073261906

3. Stroke Prevention in Atrial Fibrillation Study Group Investigators. Preliminary report of the Stroke Prevention in Atrial Fibrillation Study. N Engl J Med. 1990;322(12):863-8. https://doi.org/10.1056/ nejm199003223221232
4. Stroke Prevention in Atrial Fibrillation Study Group Investigators Warfarin versus aspirin for prevention of thromboembolism in atrial fibrillation: Stroke Prevention in atrial fibrillation: Stroke Prevention in Atrial Fibrillation II Study. Lancet. 1994;343(8899):687-91.

5. Stroke Prevention in Atrial Fibrillation Study Group Investigators. Adjusteddose warfarin versus low-intensity, fixed dose varfarin plus aspirin for high risk patients with atrial fibrillation: Stroke Prevention in Atrial Fibrillation III randomised clinical trial. Lancet. 1996;348(9028):633-8.

6. Petersen P, Boysen G, Godtfredsen J, Andersen ED, Andersen B. Placebocontrolled, randomized trial of warfarin and aspirin for prevention of thromboembolic complications in chronic atrial fibrillation. The Copenhagen AFASAK study. Lancet. 1989;1(8631):175-9. https:// doi.org/10.1016/s0140-6736(89)91200-2 
7. Kistler JP, Singer DE, Millenson MM, Bauer KA, Gress DR, Barzegar S, et al. Effect of low-intensity warfarin anticoagulation o level of activity of hemostatic system in patients with atrial fibrillation. BAATAF Investigators. Stroke. 1993;24(9):1360-5. https://doi.org/10.1161/01.STR.24.9.1360

8. Ezekowitz MD, Bridgers SL, James KE, Carliner NH, Colling CL, Gornick CC, et al. Warfarin in the prevention of stroke associated with nonrheumatic atrial fibrillation. Veterans Affairs Stroke Prevention in Nonrheumatic Atrial Fibrillation Investigators. N Engl J Med. 1992;327(20):1406-12. https://doi.org/10.1056/nejm199211123272002

9. Connolly SJ, Laupacis A, Gent M, Roberts RS, Cairns JA, Joyner C. Canadian Fibrillation Anticoagulation (CAFA) Study. J Am Coll Cardiol. 1991;18(2):349-55. https://doi.org/10.1016/0735-1097(91)90585-w

10. Ruff CT, Giugliano RP, Braunwald E, Hoffman EB, Deenadayalu N, Ezekowtiz MD, et al. Comparison of the efficacy and safety of new oral anticoagulants with warfarin in patients with atrial fibrillation: a meta-analysis of randomized trials. Lancet. 2014;383(9921):955-62. https://doi.org/10.1016/s0140-6736(13)62343-0

11. Chugh SS, Havmoeller R, Narayanan K, Singh D, Rienstra M, Benjamin EJ, et al. Worldwide epidemiology of atrial fibrillation: A Global Burden of Disease 2010 Study. Circulation. 2014;129(8):837-47. https:// dx.doi.org/10.1161\%2FCIRCULATIONAHA.113.005119

12. Cerasuolo JO, Montero-Odasso M, Ibañez A, Doocy S, Lip GY, Sposato LA. Decision-making interventions to stop the global atrial fibrillationrelated stroke tsunami. Int J Stroke. 2017;12(3):222-8. https://doi. org/10.1177/1747493016687579

13. Frank B, Fulton R, Weimar C, Shuaib A, Lees KR, VISTA Collaborators. Impact of atrial fibrillation on outcome in thrombolyzed patients with stroke evidence from the Virtual International Stroke Trials Archive (VISTA). Stroke. 2012;43(7):1872-7. https://doi.org/10.1161/ strokeaha.112.650838

14. Lin H-J, Wolf PA, Kelly-Hayes M, Beiser AS, Kase CS, Benjamin EJ, et al. Stroke severity in atrial fibrillation: The Framingham study. Stroke. 1996;27(10):1760-4. https://doi.org/10.1161/01.str.27.10.1760

15. Marcolino M, Palhares D, Benjamin E, Ribeiro A. Atrial fibrillation: prevalence in a large database of primary care patients in Brazil. EP Europace. 2015;17(12):1787-90. https://doi.org/10.1093/europace/euv185

16. Fornari LS, Calderaro D, Nassar IB, Lauretti C, Nakamura L, Bagnatori $\mathrm{R}$, et al. Misuse of antithrombotic therapy in atrial fibrillation patients: frequent, pervasive and persistent. J Thromb Thrombolysis. 2007;23(1):65-71. https://doi.org/10.1007/s11239-006-9012-9
17. Bartholomay E, Polli I, Borges AP, Kalil C, Arroque A, Kohler I, et al. Prevalence of oral anticoagulation in atrial fibrillation. Clinics. 2014;69(9):615-20. https://doi.org/10.6061/clinics/2014(09)07

18. Ogilvie IM, Newton N, Welner SA, Cowell W, Lip GY. Underuse of oral anticoagulants in atrial fibrillation: a systematic review. Am J Med. 2010;123(7):638-45.e4. https://doi.org/10.1016/j.amjmed.2009.11.025

19. Kakkar AK, Mueller I, Bassand JP, Fitzmaurice DA, Goldhaber SZ, Goto $S$, et al. Risk profiles and antithrombotic treatment of patients newly diagnosed with atrial fibrillation at risk of stroke: perspectives from the international, observational, prospective GARFIELD registry. PloS One. 2013;8(5):e63479. https://doi.org/10.1371/journal.pone.0063479

20. Man-Son-Hing M, Nichol G, Lau A, Laupacis A. Choosing antithrombotic therapy for elderly patients with atrial fibrillation who are at risk for falls. Arch Intern Med. 1999;159(7):677-85. https://doi.org/10.1001/ archinte.159.7.677

21. Gage BF, Birman-Deych E, Kerzner R, Radford MJ, Nilasena DS, Rich $M W$. Incidence of intracranial hemorrhage in patients with atrial fibrillation who are prone to fall. Am J Med. 2005;118(6):612-7. https://doi.org/10.1016/j.amjmed.2005.02.022

22. Gallagher P, Ryan C, Byrne S, Kennedy J, O'Mahony D. STOPP (Screening Tool of Older Person's Prescriptions) and START (Screening Tool to Alert doctors to Right Treatment). Consensus validation. Int J Clin Pharmacol Ther. 2008;46(2):72-83. https://doi.org/10.5414/cpp46072

23. Mant J, Hobbs FR, Fletcher K, Roalfe A, Fitzmaurice D, Lip GY, et al Warfarin versus aspirin for stroke prevention in an elderly community population with atrial fibrillation (the Birmingham Atrial Fibrillation Treatment of the Aged Study, BAFTA): a randomised controlled trial. Lancet. 2007;370(9586):493-503. https://doi.org/10.1016/s01406736(07)61233-1

24. Rahman F, Kwan G, Benjamin E. Global epidemiology of atrial fibrillation. Nat Rev Cardiol. 2014;11(11):639-54. https://doi. org/10.1038/nrcardio.2014.118

25. Pietra GLD, Savio K, Oddone E, Reggiani M, Monaco F, Leone MA. Validity and Reliability of the Barthel Index Administered by Telephone. Stroke. 2011;42(7):2077-9. https://doi.org/10.1161/strokeaha.111.613521

26. Dauphinot V, Boublay N, Moutet C, Achi S, Bathsavanis A, KrolakSalmon P. Comparison of Instrumental Activities of Daily Living assessment by face-to-face or telephone interviews: a randomized, crossover study. Alzheimers Res Ther. 2020;12(1):24-34. https://doi. org/10.1186/s13195-020-00590-w 